\title{
Preference Evaluation System for Construction Products Using QFD-TOPSIS Logic by Considering Trade-Off Technical Characteristics
}

\author{
Jaeho Cho, ${ }^{1}$ Jaeyoul Chun, ${ }^{1}$ Inhan Kim, ${ }^{2}$ and Jungsik Choi ${ }^{2}$ \\ ${ }^{1}$ Department of Architectural Engineering, Dankook University, 152, Jukjeon-ro, Suji-gu, Yongin-si, Gyeonggi-do 16890, \\ Republic of Korea \\ ${ }^{2}$ Department of Architecture, Kyung Hee University, 1732, Deogyeong-daero, Giheung-gu, Yongin-si, Gyeonggi-do 446-701, \\ Republic of Korea \\ Correspondence should be addressed to Jungsik Choi; jungsikchoi@gmail.com
}

Received 29 August 2016; Accepted 30 October 2016; Published 26 January 2017

Academic Editor: Anna M. Gil-Lafuente

Copyright (C) 2017 Jaeho Cho et al. This is an open access article distributed under the Creative Commons Attribution License, which permits unrestricted use, distribution, and reproduction in any medium, provided the original work is properly cited.

\begin{abstract}
This paper investigates the feasibility of quality function deployment, technique for the order of preference by similarity to ideal solution (QFD-TOPSIS) in presenting user preferences for multiple alternatives, such as construction technologies, products, systems, and design solutions, with trade-off technical characteristics (TC). The original QFD as house of quality (HOQ) defines the requirements and features as subjective matrix relations, which cause interpretations to vary across users and limit its industrial applications. QFD-TOPSIS is a new model that combines the benefits of QFD with those of TOPSIS, maintains the subjectivity and objectivity evaluation of the technical characteristics (TC), and rates the preferences by considering users' individual propensity for requirements. In addition, QFD-TOPSIS rates the preferences through the reciprocal compensation effects of trade-off TC and filters unsuitable alternatives with predefined restrictive conditions. Trade-off refers to conflicts and/or contradictions between attributes, often arising in multicriteria decision-making. Users or project stakeholder groups define the priorities of trade-off TC that directly influence product preferences and decision-making. In the present study, we have developed a Web system based on the QFD-TOPSIS logic and tested its operation to verify its industrial applicability and viability for automatic quality evaluation.
\end{abstract}

\section{Introduction}

Decision-making refers to the identification and selection of the best solution among several alternatives based on various factors reflecting the decision-maker's expectations [1].

The complex interrelationships that exist among various selection criteria make material selection a challenging and time-consuming task for designers [2]. The designers and project participants involved in construction work require decision-making processes for suitable selections from numerous designs, technologies, and product solutions. Suitable decision-making in construction work of the required quality reduces the design changes because unsuitable and dissatisfactory design solutions are recognized and eliminated during the design stage; therefore, the productivity of the construction project is improved.
In terms of the technologies or products of construction projects, the quality evaluation process starts with an analysis of multiple technical characteristics (TC) and criteria. When the quality of a product is being evaluated, a conflict may often occur such that the improvement of one TC could lead to degradation of other characteristics. Although an ideal solution involves the achievement of the highest level for all attributes, in real-world applications, one of the attributes may be limited by the others.

Presently, the occurrence of preference-related issues in the trade-off problem occurs inevitably due to the noncommensurable characteristics among the concerned attributes; therefore, the value of the compensation effect should be considered from the viewpoint of the required functions that are simultaneously lost and secured. Trade-off problems have been appearing in a variety of industries [3-5]. 
Various mathematical models have been proposed for multicriteria decision-making (MCDM), including analytic hierarchy process (AHP, 1970s) [6], additive ratio assessment (ARAS, 2010) [7], best-worst method (BWM, 2015) [8], characteristic-objects method (COMET, 2014) [9], complex proportional assessment of alternatives (COPRAS, 1996) [10], dominance-based rough-set approach (DRSA, 2001) [11], evaluation based on distance from average solution (EDAS, 2015) [12], elimination and choice translating reality: elimination et choix tradusiant la realite (ELECTRE, 1960s) [13], evidential-reasoning approach (ER, 1976) [14], gray relational analysis (GRA, 2007) [15], multiattribute utility theory (MAUT, 1970s) [16], multiobjective optimization on the basis of ratio analysis (MULTIMOORA, 2006) [17], preference ranking organization method for enrichment evaluation (PROMETHEE, 1982) [18], stochastic multicriteria acceptability analysis (SMAA, 2001) [19], superiority and inferiority ranking (SIR, 2004) [20], TODIM (an acronym in Portuguese of Interactive and Multicriteria Decision-Making, 2014) [21, 22], technique for the order of preference by similarity to ideal solution (TOPSIS, 1981) [23-25], and VIseKriterijumskaOptimizacija I KompromisnoResenje (VIKOR, 1979) [26, 27]. ARAS, COPRAS, EDAS, ELECTRE, MULTIMOORA, and TODIM are similar methods with TOPSIS from a structural perspective. The MCDM models have been applied to optimal selection problems in various industrial and engineering fields.

Among the MCDM methods, quality function deployment (QFD), TOPSIS, and MAUT address the abovementioned trade-off problem. QFD is a tool that can be used to define effectively the trade-off characteristics of a product. Here, the TC of the trade-off are only clarified using the house of quality (HOQ) model, and the value of the trade-off is not measured quantitatively in view of the compensation effect. TOPSIS only evaluates preferences in terms of TC and does not specify the trade-off problem. MAUT is a structured methodology that is designed to handle trade-offs among multiple objectives. One of the first applications of MAUT involved a study of alternative locations for a new airport in Mexico City during the early 1970s [28].

In terms of the trade-off problem, MAUT sets an environment of uncertainty and thus evaluates the preference of each user according to an uncertainty/risk-based approach; therefore, MAUT is not suitable for real-world applications because quality evaluation of technologies and products should produce both objective and quantitative results.

This study proposes the QFD-TOPSIS model in which the QFD model is combined with TOPSIS to measure tradeoff TC. The QFD-TOPSIS model specifies the trade-off TC and analyzes the preferences by comparing common TC of multiple product solutions. If the trade-off is specified in relation to TC, intercompensation effects based on the users' weights are determined. Furthermore, the weights can be modified according to the user environment.

This case study is a follow-up of our previous work "QFDBased Benchmarking Logic Using TOPSIS and Suitability Index" [29].

\section{QFD and TOPSIS}

2.1. Theory and Limitation of QFD. As described by Dr. Akao, QFD is a "method to transform qualitative user demands into quantitative parameters, to deploy the functions forming quality, and to deploy methods for achieving the design quality into subsystems and component parts, and ultimately to specific elements of the manufacturing process." [30]. Akao originally developed QFD in Japan in 1966 by combining his work on quality assurance and quality control with the function deployment approach used in value engineering.

The extent of the areas in which QFD has been researched has become so exhaustive that Carnevalli and Miguel (2008) investigated QFD research as a research topic itself [31]. In particular, the QFD model has been applied to a variety of industrial fields for which the focus is MCDM. QFD is recognized as an excellent tool that allows for a comprehensive assessment of quality in consideration of multiple performance attributes and gathers the project stakeholder requirements [32].

QFD for decision-making has been commonly studied in combination with other decision-making models, for example, a decision-making model that combines QFD and fuzzy theory [33-37]; a decision-making model that combines fuzzy-based QFD and the analytic network process (ANP) [38]; and a decision-making model that combines QFD and ANP [39]. Furthermore, the Kano [40], DEA [41], rough set [42], Simple Multiattribute Rating Technique (SMART) [43], conjoint analysis [44], Multiattribute Value (MAV) [45], and Fuzzy Analytic Hierarchy Process (FAHP) [37] models have all been used in QFD for the design of quality assessment methods, where the focus is on relative comparison among the products.

Although studies on QFD are currently underway, reviews of the literature have noted difficulties in the use of quality plans according to QFD [31]. The major methodological difficulties here are related to the stage of elaboration of the quality matrices, for example, "interpreting the customer voice" [46], "identifying the most important customer demands" [47], and "project decision making, since correlations among the demands are not clear" [36]. It has been noted that alleviating the methodological difficulties in the development of the quality matrix is a key factor in encouraging and expanding the use of QFD [31].

In particular, a problem arises when different quality assessment results are derived depending on the quality matrix that is applied for the house of quality (HOQ). This fundamental cause of different evaluation results has led to the subjective creation of the "HOQ quality matrix."

According to the original design, the creation of the "HOQ of QFD" should be based on user experience. The customer needs with regard to the "what" can be crosschecked against the related design TC of the "how." The core matrix of QFD of HOQ is shown in Figure 1 [48].

2.2. Theory and Limitation of TOPSIS. Being a type of MCDM, TOPSIS presents the preferences of alternative solutions. TOPSIS is usually employed for relative comparison of alternatives [23, 49]. It calculates a value that represents the distance between a positive ideal solution (PIS) and a negative ideal solution (NIS). Hwang and Yoon (1981) [23] 


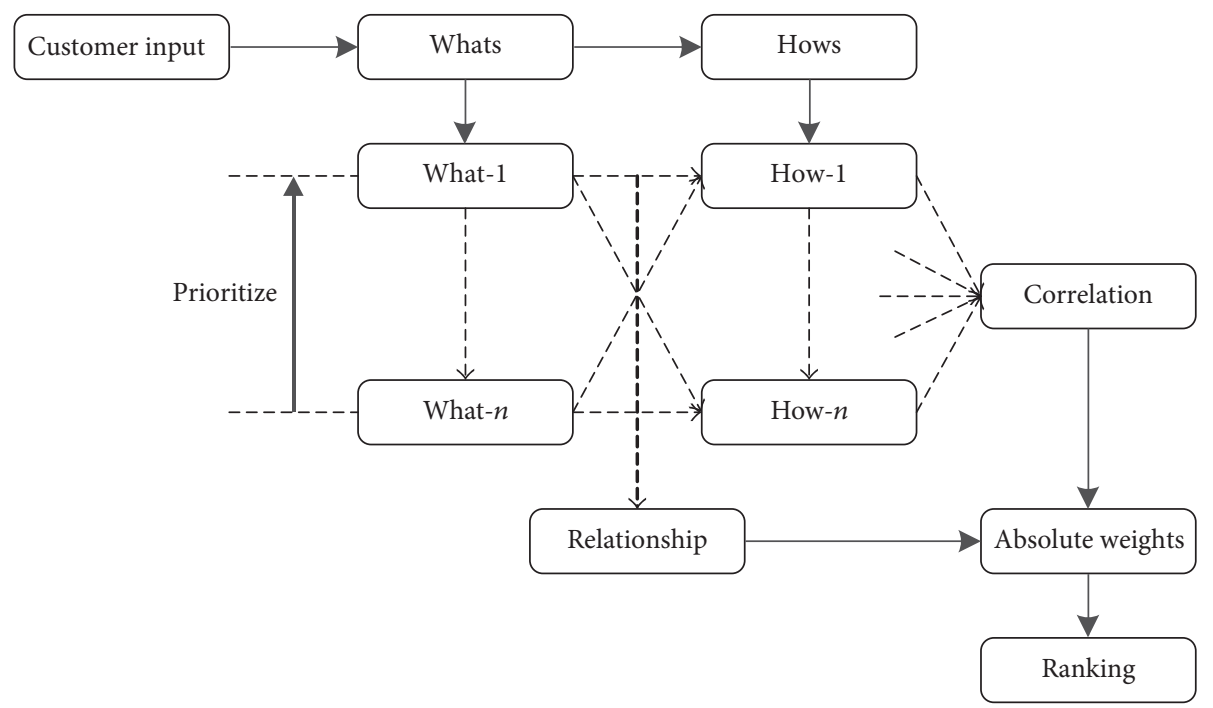

FIGURE 1: Conceptual map of the original QFD matrix.

originally proposed the TOPSIS method for the identification of solutions from a finite set of alternatives. The details of the traditional TOPSIS solution have been presented by Li et al. [50].

TOPSIS assigns preference ranks while considering multiple properties of a product, service, or system. The preference refers to scores that are distributed between 0 and 1. The quality improves as the preference score approaches 1. An assumption made with regard to TOPSIS is that the criteria are monotonically increasing or decreasing. TOPSIS requires normalization, because the parameters or criteria of the products generally consist of incongruous dimensions $[51,52]$.

TOPSIS, as a compensatory method, allows for tradeoff solutions, where poor performance of one attribute can be negated by sound results of another attribute. This approach provides more realistic evaluation results than noncompensatory methods. TOPSIS is based on the following assumptions:

(1) The value of each criterion is linearly decreasing or increasing.

(2) The criteria are independent.

In contrast to the above assumptions, the trade-off criterion itself is a dependent relation between the criteria. The values are determined to be associated with each other. TOPSIS considers the trade-off problem internally only; it does not represent the trade-off directly. Therefore, it is difficult for the user to determine which criteria are more important in the trade-off problem.

The advantage of the denotation of the trade-off relationship is that the user helps to prioritize trade-off TC in consideration of the project environment. This function allows the decision maker (DMr) to select the best solution through users' customized weights while keeping the objective evaluation value of TC.

\section{QFD-TOPSIS Model}

3.1. Apply Compensation Effect to Trade-off TC. This study proposes an advanced model of a preference evaluation system considering the trade-off TC problem through a combination of QFD and TOPSIS benefits. Although QFDHOQ is a powerful tool for product quality planning, it is not directly applied to alternatives evaluation, comparison, and value engineering (VE). In contrast, TOPSIS is a straightforward and strong tool for trade-off issues and alternatives comparison. Both QFD and TOPSIS are based on TC. Thus, both can draw on the common TC to integrate the respective models into one and apply the compensation effects as defined trade-off TC.

A TC of trade-off is defined by a pair of TC that are in conflict with each other. In the trade-off of TC, the value of one TC approaches a negative value as the value of the other TC approaches the ideal value. In general, a trade-off is defined as a relationship between a pair of TC; however, a conflict may occur within one of the TC itself when the TC has two different functions.

Trade-off TC is presented in the form of correlation functions such as those given by (1)-(3) below. The tradeoff values distinguish the corresponding distance interval for each TC and use at least one of the following equations for each distance interval:

$$
y\left(x_{i j}\right)=a-b * \exp \left(c x_{i j}\right)
$$

(monotone increasing, toward minimum $x$ value),

$$
y\left(x_{i j}\right)=a-b *\left(x_{i j}\right) \text {, }
$$

(inverse proportion, when $b=1$ ),

$y\left(x_{i j}\right)=a+b * \exp \left(c x_{i j}\right)$,

(monotone decreasing, toward maximum $x$ value). 
Here, $a$ and $b$ are positive constants such that " $y(x)$ is 0 or a positive constant." Furthermore, $c$ is a positive constant such that $0<c<1$.

Figure 2 shows the preference measurement approach applied to the effect of compensation in trade-off TC using the combined QFD and TOPSIS logic.

3.2. Relationship of Function, TC, and TC Criteria. In realworld applications, the functions and TC of products may be represented as $n: n$ relationships. This method is used in the original QFD-HOQ.

Figure 3 shows the $n: n$ relationships among the function class, TC class, and TC criteria of a product by an overlapping map of QFD-HOQ. Based on Figure 3, the relationship of the relevant class is described as follows:

(1) The function factor of $\mathrm{f}(4)$ is associated with the $\mathrm{TC}$ (master) of $\mathrm{D}$ in a $1: 1$ relationship, and $\mathrm{f}(4)$ is simultaneously composed of the elements of function C.

(2) One function element can have one or one more TC elements.

(3) In addition, the function class of one TC is different from that of another TC, that is, theoretically, a unique function class applies to only one TC(master) element.

(4) The TC are all independent except for the trade-off TC.

(5) TC(B) and TC(C) form a pair of trade-off TC.

(6) TC(E) has a self-contradictory trade-off, as it has two different functions: $\mathrm{F}(6)$ and $\mathrm{F}(7)$.

The $n: n$ relational structure of the function and TC has itself limitations with respect to objectivity because each user would define matrix in QFD-HOQ differently. This leads to different quality planning and evaluation for the end user. In TC evaluation, however, the 1:1 relationship of function and TC enables each user to maintain consistent interpretations and to share objectivity.

The TC can be used as common class in QFD and TOPSIS. The TC always apply an objective analysis to any user. Thus, it is possible to define TC as a unique (inherent) attribute and to define the function from the TC perspective. Until now, from the view of the function, the function can have multiple TC elements. It leads to the result in the subjective matrix in HOQ. However, the way of the unique TC definition can be defined as not only a single function element but also multiple function elements. It can lead to the result in the objective matrix in HOQ.

Figure 4 shows a conceptual schematic diagram, where the TC(master) class is broken down into sublevel TC(sub). Here, every $\mathrm{TC}(\mathrm{sub})$ has a $1: 1$ relationship with a unique (inherent) function element or component. In addition, it is possible to specify the trade-off TC at the TC(sub) level. Figure 4 shows the denotation of the trade-off relations among the TC and the self-contradictory trade-off relation in one TC(master) by creating pairs of TC(sub).
3.3. QFD Deployment for QFD-TOPSIS. QFD is not just intended for application of HOQ. HOQ is no more than a sample among the development models of QFD. The original QFD starts from HOQ and then develops again in each production step. QFD enables the design of quality into a product in a formalized manner through four main planning stages: product, parts, manufacturing process, and production operations planning [53]. The original approach, called the "matrix of matrices," relies on a rectangular arrangement of data into rows and columns for the organization, analysis, and development of information relating to a product being considered for design [54].

The deployment of QFD-TOPSIS consists in four steps referenced from the original QFD approach. The first step configures the HOQ using function requirements and TC. The second step sets up the 1:1 relation with $\mathrm{TC}(\mathrm{sub})$, defines the trade-off TC(sub), and determines the correlation function of the trade-off TC(sub). The third step builds a matrix of multiple alternatives from a market product, target values, and thresholds of TC(sub). The fourth step builds a weighted TC matrix for preference analysis. Figure 5 shows the 4-step conceptual schematic diagram in order to complete QFD-TOPSIS starting from HOQ.

The matrix items of QFD-TOPSIS are described as follows:

(a) F. weight: determines the function weight of a product. The weight lies between 0 and 10 .

(b) Limit: defines the limit value of TC(sub).

(c) Normalization value: intercompares market products by normalizing the TC(sub) values. The normalized values lie between 0 and 1 .

(d) Market products: list the market products that are to be compared as design alternatives.

(e) Positive ideal value and negative ideal value: define the positive ideal value and negative ideal value of TC(sub).

(f) Product preference: analyzes the preferences of market products. The values of the preferences lie between 0 and 1 ; the closer the value is to 1 , the higher the preference is.

(g) Target: defines the target value of TC(sub).

(h) TC relation: denotation of the trade-off between $\mathrm{TC}(\mathrm{sub})$ that is a self-contradictory trade-off or a pair of trade-off TC.

(i) TC(master): defines the concept of upper classification regarding $\mathrm{TC}$ of a product.

(j) TC(sub): defines the concept of subclassification regarding TC of a product.

(k) TC weight: determines the weight of TC(sub) corresponding to the product. The weight lies between 0 and 10 .

(l) Restriction filter: a TC(sub) is considered an unfit feature when it is consistent with the restrictive condition. Any unsuitable feature is excluded from the alternatives for selection. 


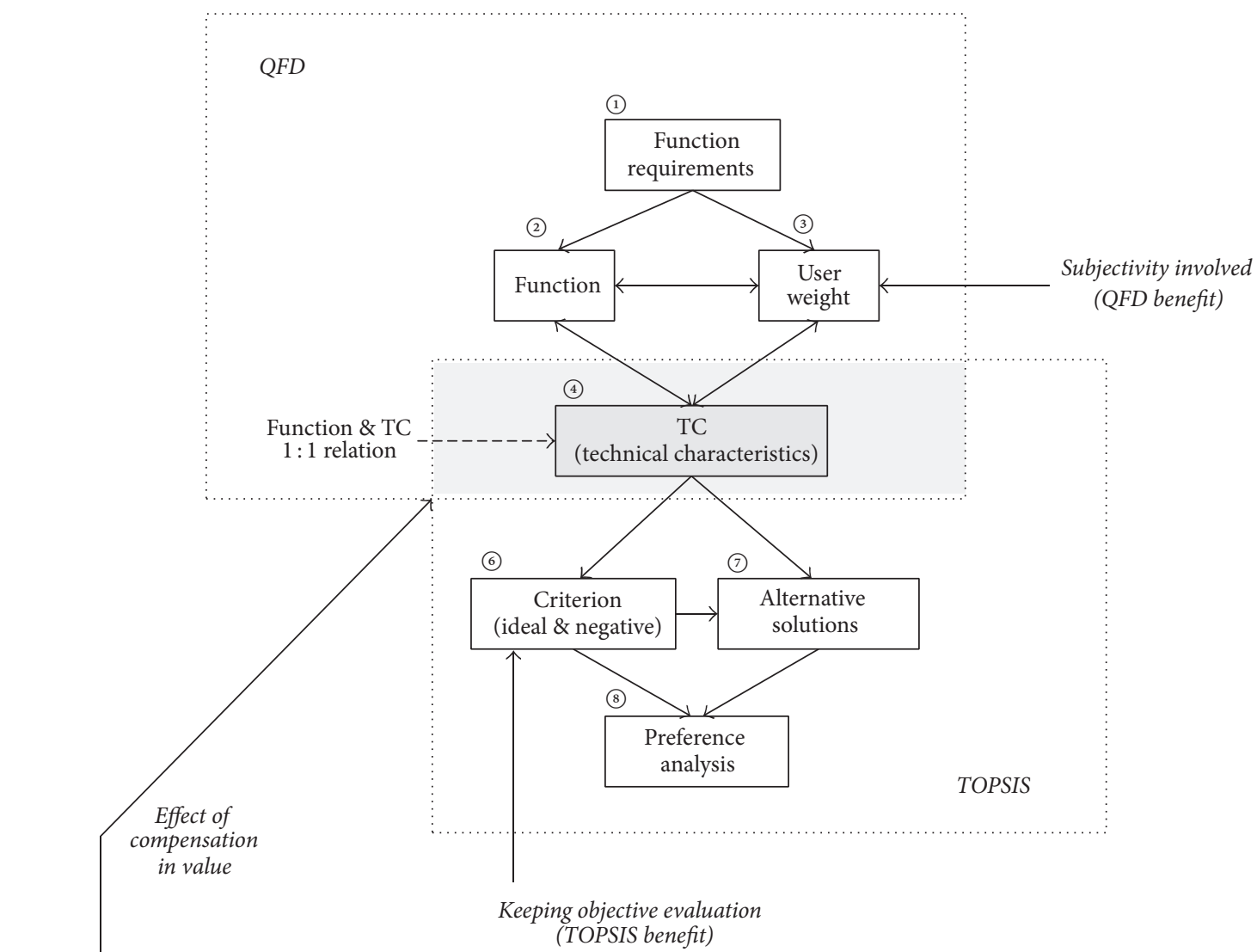

Self-contradictory trade-off TC

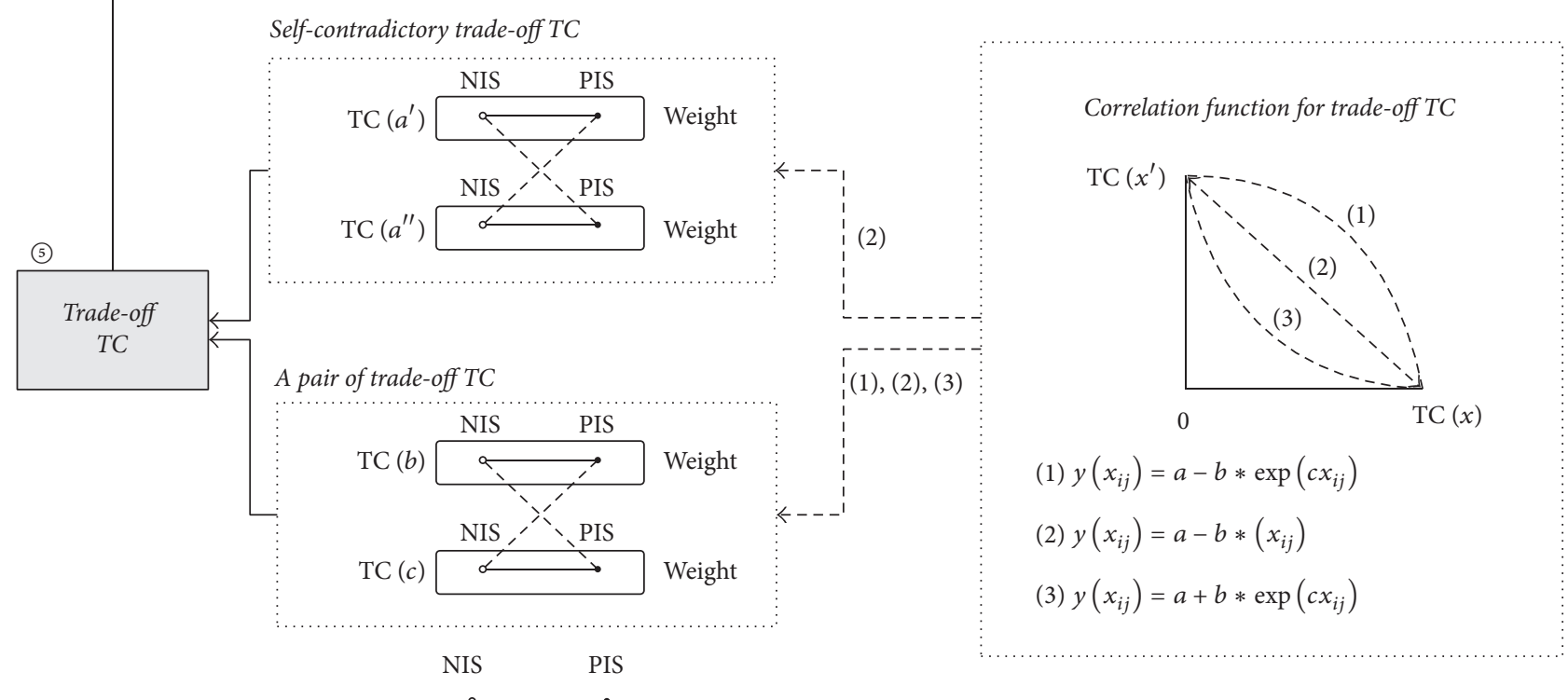

NIS (negative ideal solution)

PIS (positive ideal solution)

FIGURE 2: Preference evaluation model in a trade-off TC problem using the combined QFD and TOPSIS benefit. 
Relation matrix of function and TC in QFD-HOQ

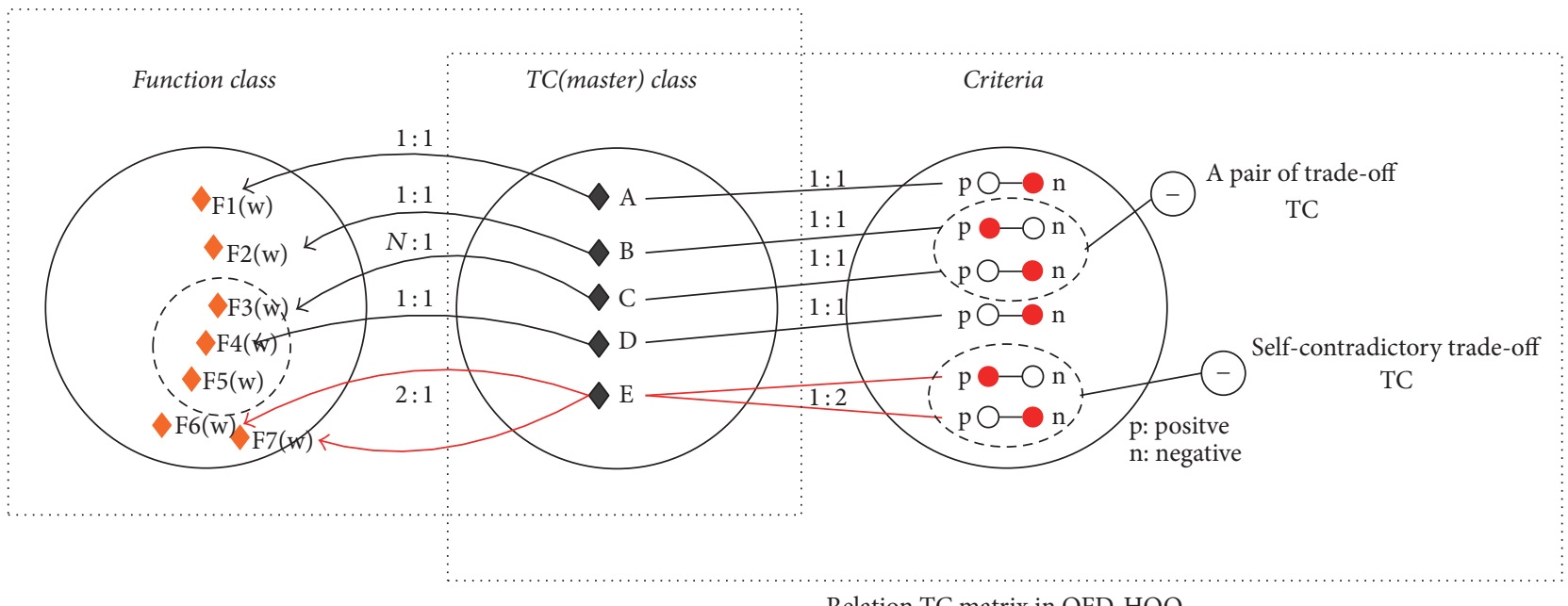

Relation TC matrix in QFD-HOQ

FIGURE 3: The original QFD-HOQ approach in terms of relationships and trade-off.

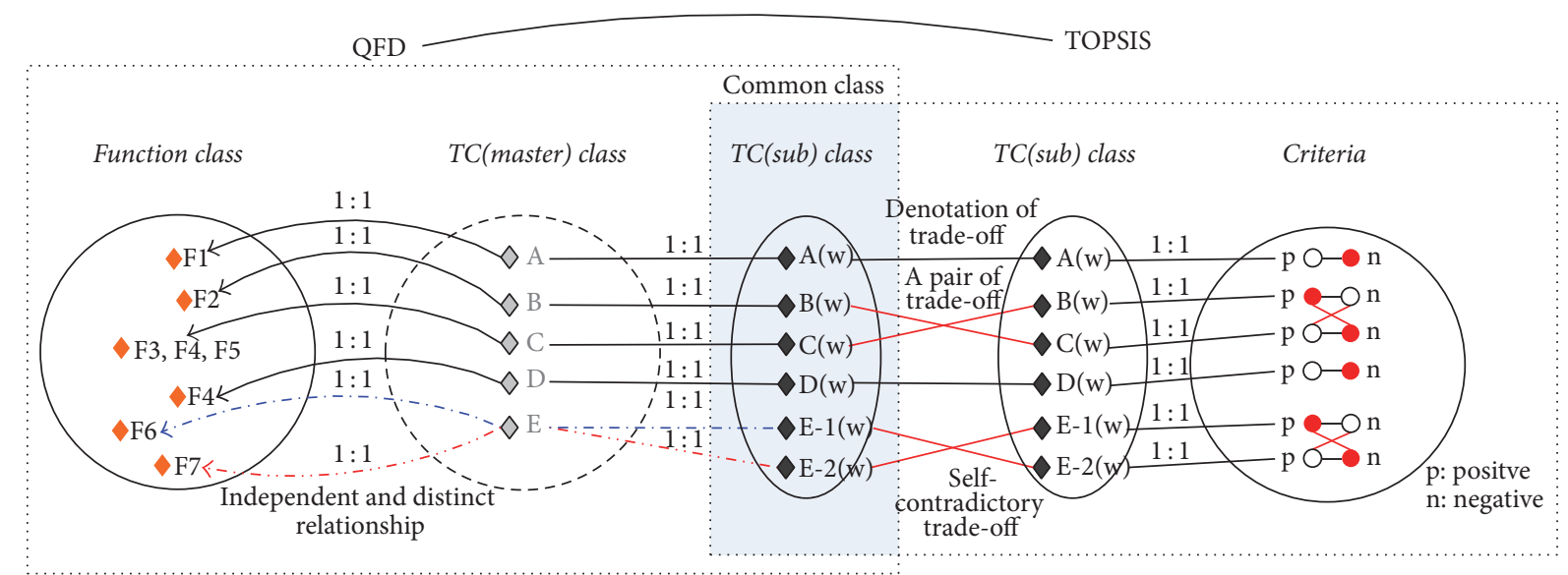

FIGURE 4: Explicit expression for a pair of trade-off TC(sub) and self-contradictory trade-off TC(sub).

\section{QFD-TOPSIS Mathematical Logic}

The logic of QFD-TOPSIS is as follows.
Step 1 (defining $m$ alternative products and $n$ units of "TC(master)"). The cross-matrix $D$ is composed of $n$ units of TC with respect to $m$ units of products, a targeting alternative, and a limited alternative.

$$
\begin{aligned}
& \begin{array}{llll}
X_{1} & X_{2} & \cdots & X_{n}
\end{array} \\
& D=\begin{array}{c}
A_{1} \\
A_{2} \\
\vdots \\
A_{m}
\end{array}\left[\begin{array}{cccc}
x_{11} & x_{12} & \cdots & x_{1 n} \\
x_{21} & x_{22} & \cdots & x_{2 n} \\
\vdots & \vdots & \vdots & \vdots \\
\vdots & \vdots & \vdots & \vdots \\
x_{m 1} & x_{m 2} & \cdots & x_{m n}
\end{array}\right] \\
& \begin{array}{l}
A_{g} \\
A_{l}
\end{array} \quad\left[\begin{array}{llll}
x_{g 1} & x_{g 2} & \ldots & x_{g n} \\
x_{l 1} & x_{l 2} & \ldots & x_{l n}
\end{array}\right] \text {. }
\end{aligned}
$$




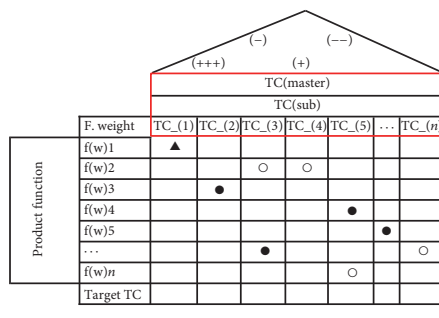

(1) Deployment ${ }^{*} n: n$ relationship

Quality deployment matrix

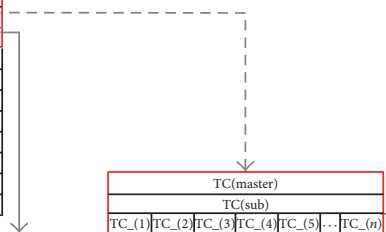

TC relation deployment matrix

(1), (2)

(2) Deployment

${ }^{*} 1: 1$ relationship

${ }^{*}$ Trade-off definition

${ }^{*}$ TC correlation function

Presentation $<1>$ definition TC \& function relation

\begin{tabular}{|c|c|c|c|c|c|}
\hline $\operatorname{ten}$ & \begin{tabular}{|l}
$\mathrm{ITC(master)}$ \\
\end{tabular} & TTC(sub) & Weight: & \begin{tabular}{|l|l|} 
Priority \\
\end{tabular} & 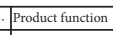 \\
\hline & TC_m(1) & & $f(W) 1$ & & \\
\hline & $\mathrm{TC}_{\mathrm{T}} \mathrm{m}(2)$ & $\mathrm{TTC} s(2)$ & $f(W) 2$ & & $f(2)$ \\
\hline & $\mathrm{TC} \mathrm{T}_{\mathrm{m}}(3)$ & $\mathrm{TTC} s(3)$ & $f(W)^{3}$ & & $f(3)$ \\
\hline 4 & TC_m(4) & TC_s $s(4)$ & $f(W) 4$ & & $f(4)$ \\
\hline & TC_m(5) & TTC $s(5)$ & $f(W) 5$ & & $f(5)$ \\
\hline & & & & & \\
\hline & \begin{tabular}{|l|} 
TC_m $(n)$ \\
\end{tabular} & TC_s $\_(n)$ & $f(W) n$ & & $f(n)$ \\
\hline
\end{tabular}

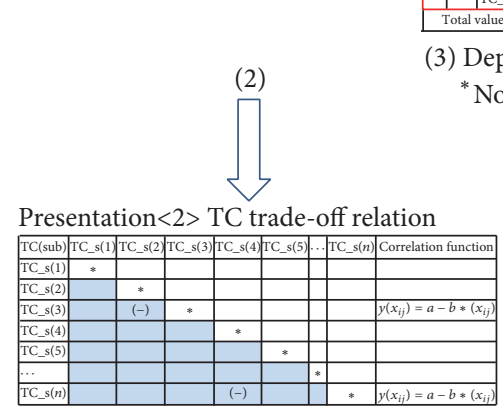

(3), (4)

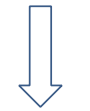

(4) Deployment

${ }^{*}$ Weighting value

Preference evaluation matrix

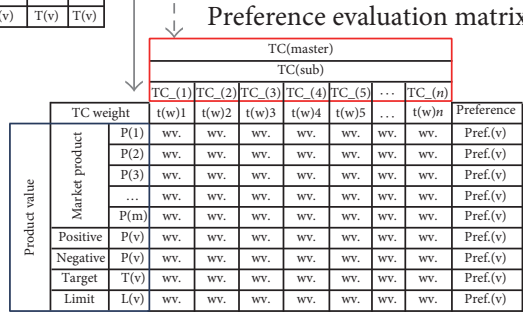

Presentation $<3>$ products preference and suitability

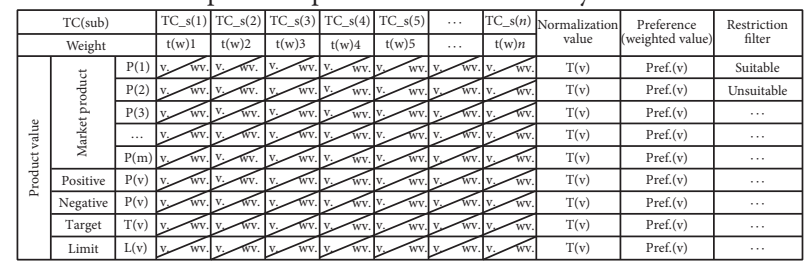

FIGURE 5: QFD deployment for the QFD-TOPSIS model.

In (4), $A_{i}$ denotes the $i$ th "product," $X_{j}$ denotes the $j$ th "TC(master)" of the relevant product, $X_{i j}$ denotes product $A_{i}$ of the $j$ th "TC(master) value," $A_{g}$ denotes the "target product" with the "target value of TC(master)," and $A_{l}$ denotes the "limit product" with the "limit or minimum value of TC(master)." Here, $i$ can define up to $m$ units and $j$ up to $n$ units.

Step 2 (setting $k$ units of TC(sub) dependent on TC(master) existence of the self-contradictory trade-off).

$$
\begin{aligned}
& \begin{array}{llll}
X_{1}^{\prime} & X_{2}^{\prime} & \cdots & X_{k}^{\prime}
\end{array} \\
& D^{\prime}=\begin{array}{c}
A_{1} \\
A_{2} \\
\vdots \\
\vdots \\
A_{m}
\end{array}\left[\begin{array}{cccc}
x_{11}^{\prime} & x_{12}^{\prime} & \cdots & x_{1 k}^{\prime} \\
x_{21}^{\prime} & x_{22}^{\prime} & \cdots & x_{2 k}^{\prime} \\
\vdots & \vdots & \vdots & \vdots \\
\vdots & \vdots & \vdots & \vdots \\
x_{m 1}^{\prime} & x_{m 2}^{\prime} & \cdots & x_{m k}^{\prime}
\end{array}\right]
\end{aligned}
$$

$$
\begin{aligned}
& \left(A_{i}: i=1,2, \ldots, m, X_{j}^{\prime}: j=1,2, \ldots, k\right) \\
& \begin{array}{l}
A_{g} \\
A_{l}
\end{array} \quad\left[\begin{array}{cccc}
x_{g 1}^{\prime} & x_{g 2}^{\prime} & \cdots & x_{g k}^{\prime} \\
x_{l 1}^{\prime} & x_{l 2}^{\prime} & \cdots & x_{l k}^{\prime}
\end{array}\right] .
\end{aligned}
$$

In $2, X_{j}^{\prime}$ denotes the $j$ th "TC(sub) of the relevant product." For "TC(sub)," $j$ can define up to $k$ units. Furthermore, $k$ increases by the number of self-contradictory trade-offs of $X_{j}$ for TC(master); therefore, $k$ is always greater than or equal to $n(k \geq n)$. In addition, $x_{i j}^{\prime}$ denotes the $j$ th TC(sub) value as the raw value in product $A_{i}$.

Step 3 (setting ideal and negative value and target and limit value of "TC(sub)"). The ideal value $D^{+}$and the negative value $D^{-}$are defined as follows: 


$$
\begin{aligned}
D^{+} & =\left\{\left\langle\max \left(x_{i j}^{\prime} \mid i=1,2, \ldots, m\right) \mid j \in J^{+}\right\rangle,\right. \\
& \left.\left\langle\min \left(x_{i j}^{\prime} \mid i=1,2, \ldots, m\right) \mid j \in J^{-}\right\rangle\right\}=\left\{x_{j}^{+} \mid j\right. \\
& =1,2, \ldots, k\}, \\
D^{-} & =\left\{\left\langle\min \left(x_{i j}^{\prime} \mid i=1,2, \ldots, m\right) \mid j \in J^{+}\right\rangle,\right. \\
& \left.\left\langle\max \left(x_{i j}^{\prime} \mid i=1,2, \ldots, m\right) \mid j \in J^{-}\right\rangle\right\}=\left\{x_{j}^{-} \mid j\right. \\
& =1,2, \ldots, k\},
\end{aligned}
$$

where the following equations apply:

$$
\begin{aligned}
J^{+} & =\{j=1,2, \ldots, k \mid \\
& j \text { is associated with the criteria having a positive impact }\}, \\
J^{-} & =\{j=1,2, \ldots, k \mid
\end{aligned}
$$

$j$ is associated with the criteria having a negative impact $\}$.

Step 4 (setting trade-off relations among $\mathrm{TC}(\mathrm{sub})$ ). In the system, the trade-off relations are set at the level of TC(sub). One TC(master) $\left(x_{i j}\right)$ comprises one TC $($ sub $)\left(x_{i j}^{\prime}\right)$ as a default value. However, if TC(master) $\left(x_{i j}\right)$ is a self-contradiction scale in the trade-off, TC(sub) will be defined as two different TC(sub) $\left(x_{i j}^{\prime}, x_{i(j+1)}^{\prime}\right)$. Furthermore, TC(sub) $\left(x_{i j}^{\prime}, x_{i(j+1)}^{\prime}\right)$ have opposite values for $\max \left(x_{i j}^{\prime}\right)$ and $\min \left(x_{i(j+1)}^{\prime}\right)$ from (2).

In another case, where one pair of TC(sub) has a tradeoff relation, each $\mathrm{TC}(\mathrm{sub})$ value is defined by the relevant correlation function given by (1)-(3). The pair of trade-off $\mathrm{TC}(\mathrm{sub})$ can be represented using (8).

If TC(sub) $\left(x_{i j}^{\prime}\right)$ and TC(sub) $\left(x_{i j^{\prime}}^{\prime}\right)$ are one pair of a tradeoff relation,

$$
\begin{aligned}
& \mathrm{TC}(\mathrm{sub})\left(x_{i j}^{\prime}\right) \\
& \quad \ni x_{i j}^{\prime}\left(\text { positive ideal value }=\max \left(x_{i j}^{\prime}\right)\right), \\
& x_{i j}^{\prime}\left(\text { negative ideal value }=\min \left(x_{i j}^{\prime}\right)\right) . \\
& \qquad\left|j-j^{\prime}\right| \leq k-1
\end{aligned}
$$

$\mathrm{TC}(\mathrm{sub})\left(x_{i j^{\prime}}^{\prime}\right)$

$\ni x_{i j^{\prime}}^{\prime}\left(\right.$ positive ideal value $\left.=\max \left(x_{i j^{\prime}}^{\prime}\right)\right)$,

$$
\begin{gathered}
A_{1}^{\prime} \\
\begin{array}{c}
A_{1} \\
A_{2} \\
\vdots \\
\vdots \\
\vdots \\
A_{m}
\end{array}\left[\begin{array}{cccc}
w_{1} r_{11} & w_{2} r_{12} & \cdots & X_{k}^{\prime} \\
w_{1} r_{11} & w_{2} r_{12} & \cdots & w_{k} r_{1 k} \\
\vdots & \vdots & \vdots & \vdots \\
\vdots & \vdots & \vdots & \vdots \\
w_{1} r_{m 1} & w_{2} r_{m 2} & \cdots & w_{k} r_{m k}
\end{array}\right]=\left[\begin{array}{cccc}
X_{1}^{\prime} & X_{2}^{\prime} & \ldots & X_{k}^{\prime} \\
v_{11} & v_{12} & \cdots & v_{1 k} \\
\vdots & \vdots & \vdots & \vdots \\
\vdots & \vdots & \vdots & \vdots \\
v_{m 1} & v_{m 2} & \cdots & v_{m k}
\end{array}\right] \quad\left(A_{i}: i=1,2, \ldots, m \text { and } g, l \text { and } v_{i j}: j=1,2, \ldots, k\right) \\
A_{l}
\end{gathered}
$$




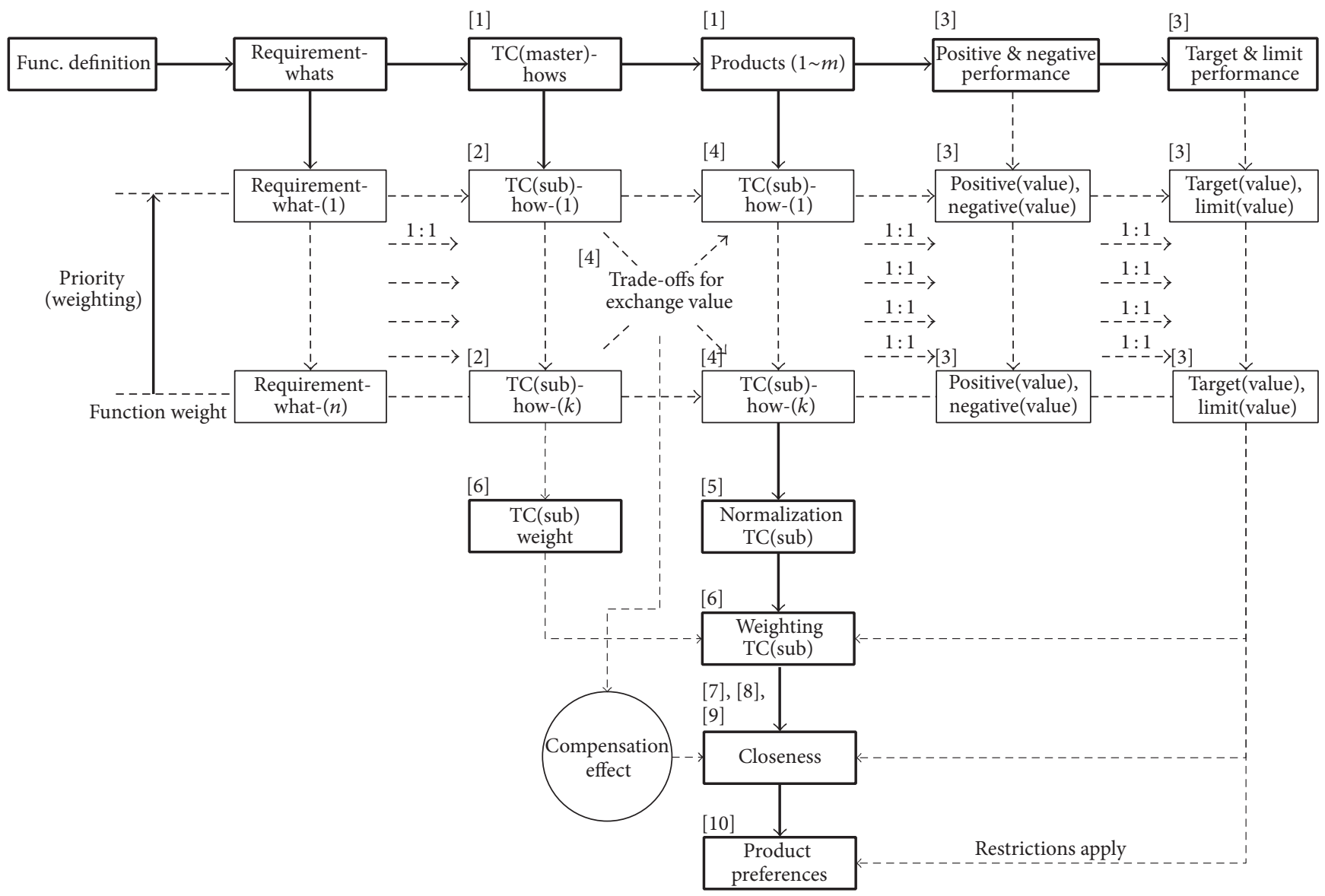

FIGURE 6: Advanced QFD-TOPSIS model from the QFD matrix.

Step 7 (calculating the maximum value of $v_{i k}$ ). The maximum value, $A_{(\max )}$, is defined as

$$
\begin{aligned}
A_{(\max )} & =\left\{\max \left(v_{j}\right) ; j=1,2, \ldots, k\right\} \\
& =\left\{v_{1}^{+}, v_{2}^{+}, \ldots, v_{k}^{+}\right\},
\end{aligned}
$$

where $A_{(\max )}$ denotes the ideal technical characteristics with the highest preference.

Step 8 (calculating the internal measure). The distance from the ideal solution, $A_{(\max )}$, for each product is calculated as

$$
S_{i}^{+}=\left[\sum_{j=1}^{k}\left(v_{i j}-v_{j}^{+}\right)^{2}\right]^{1 / 2} \quad(i=1,2, \ldots, m \text { and } g, l) \text {. }
$$

The separation from the negative solution, $A^{-}$, for each product is calculated as

$$
S_{i}^{-}=\sum_{j=1}^{k} v_{i j} \quad(i=1,2, \ldots, m \text { and } g, l) .
$$

Step 9 (calculating relative closeness from the ideal solution). The relative closeness $C_{i}$ of $A_{i}$ with respect to the ideal solution $A_{(\max )}$ is defined as

$$
C_{i}=\frac{S_{i}^{-}}{\left(S_{i}^{+}+S_{i}^{-}\right)}
$$

$$
\left(0<C_{i}<1\right),(i=1,2, \ldots, m \text { and } g, l) .
$$

As $C_{i}$ approaches $1, A_{i}$ approaches $A_{(\max )}$.

Step 10 (aligning products based on the preference value $C_{i}$ ). The order of preference for the products is determined by the size of $C_{i}$. In addition, any product consistent with the threshold of a TC(sub) is considered an unsuitable alternative and excluded from the alternatives for selection.

Figure 6 shows the conceptual process of QFD-TOPSIS that is developed from the original QFD.

\section{Verification of QFD-TOPSIS System}

In this section, we present a unified modeling language (UML) model and a test operation for the QFD-TOPSIS system. 


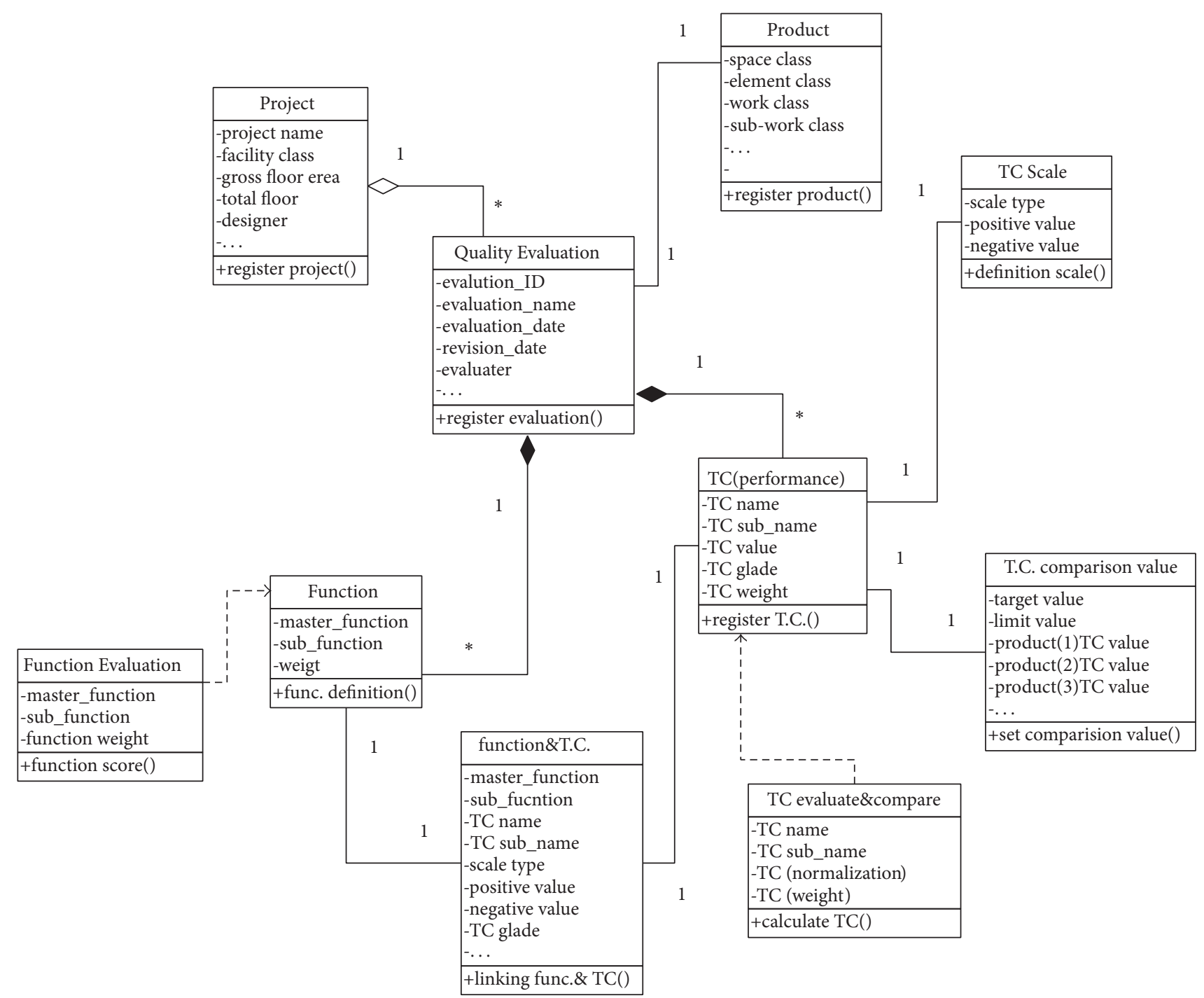

FIGURE 7: UML diagram for a QFD-TOPSIS Web-based quality evaluation system.

The users of this system include facility managers, clients, designers, engineers, contractors, and manufacturers. A single facility project may consist of multiple products or elements, while an evaluation by multiple appraisers (users, designers, engineers, contractors, etc.) applies to one product (one design solution). Moreover, the evaluation can be revised repeatedly by one or multiple appraisers (appraising team).

As shown in the UML diagram (Figure 7), the Function Evaluation class represents the dependency relationship of the function class, and the TC evaluate and compare class represents the dependency relationship of the TC(performance) class.

The quality evaluation system establishes a $1: 1$ relationship between the required functions and the TC. In turn, multiple alternatives are intercompared with regard to the function and TC in consideration of the limit or target value.

In the case study, the test data from "QFD Based Benchmarking Logic Using TOPSIS and Suitability Index" [16] was used. The test data comprises the performance values of window products for a building. The "target performance" and "limit performance" of the window products in terms of the building are arbitrarily set by the users.

The performance items consist of the following: $U$-value (glazing): interval scale, $U$-value (total): interval scale, SHGC (summer): interval scale, SHGC (winter): interval scale, VT: 5-grade scale, CR: 4-grade scale, AT: 3-grade scale, WS: binary scale, and WT: binary scale.

The $U$-value measures the amount of heat that is transferred through the window. A lower $U$-value indicates better thermal insulation performance. The $U$-value can be classified by the glass itself and the glass curtain wall including the frame.

The solar heat gain coefficient (SHGC) measures the amount of solar radiation that passes through the window. SHGC is expressed as a number between 0 and 1 . The lower the SHGC of a window, the smaller the amount of solar heat that it transmits. In terms of the users' functional 


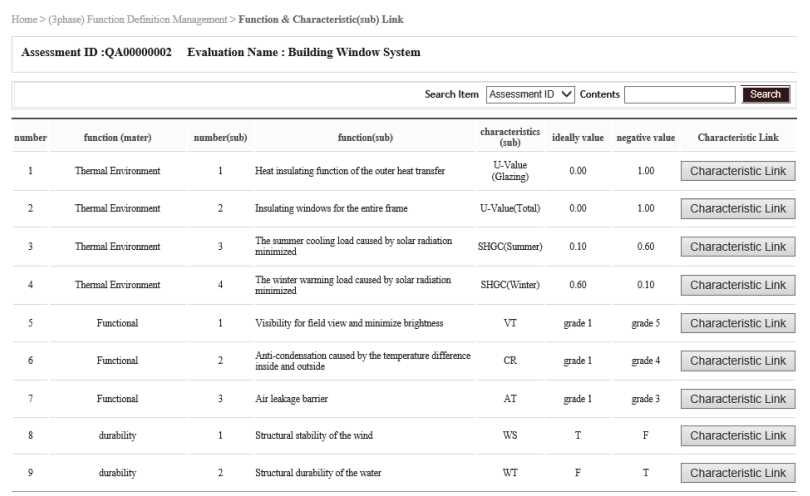

FIgURE 8: Linking of the functions and TC(sub).

requirements, SHGC can be classified into SHGC (summer) and SHGC (winter). The ideal values for SHGC (summer) and SHGC (winter) are 1 and 0 , respectively.

Visible transmittance (VT) is the amount of light in the visible portion of the spectrum that passes through a glazing material. A higher VT grade indicates a greater amount of daylight in a space. When the space is designed, the electric lighting and its associated cooling loads should be offset. VT is expressed on a five-grade scale, where grade 1 represents the highest VT performance.

Condensation resistance (CR) measures a product's resistance against condensation formation. CR is expressed on a four-grade scale, where grade 1 represents the best CR performance.

Air-tightness (AT) can be defined as the resistance to inward or outward air leakage that occurs through unintentional leakage points or areas of the building envelope. AT is expressed on a three-grade scale, where grade 1 represents the best AT performance.

Wind safety (WS) indicates the safety of a window against wind; the safety measurement follows the standards of the ASTM E330 test. In this case study, a binary scale was adopted for WS.

Water tightness (WT) indicates the window's resistance against water leakage. The amount of water leakage must be 0 based on the standards of the ASTME 331 test. In this case study, the WT was evaluated as 1 ("no leakage" as suitable) or 0 ("leakage" as unsuitable).

A screenshot of the definitions of the 1:1 relationship between the functions and TC(sub) is shown in Figure 8.

A comparison of the normalized TC values is shown in Figure 9.

The weighting TC values and a comparison of the windows are shown in Figure 10.

The completion of the cross-matrix of QFD-TOPSIS is shown in Figure 11. As subclassifications of SHGC, TC "SHGC (summer)" and "SHGC (winter)" are self-contradictory trade-off TC, which are specified in the cross-matrix. At the bottom of the cross-matrix, six market product preferences involved in the trade-off effect are listed. In addition, the target product and limit product preferences are listed. The $(c)$ and $(d)$ among the 6 products are excluded due to the restrictive condition.

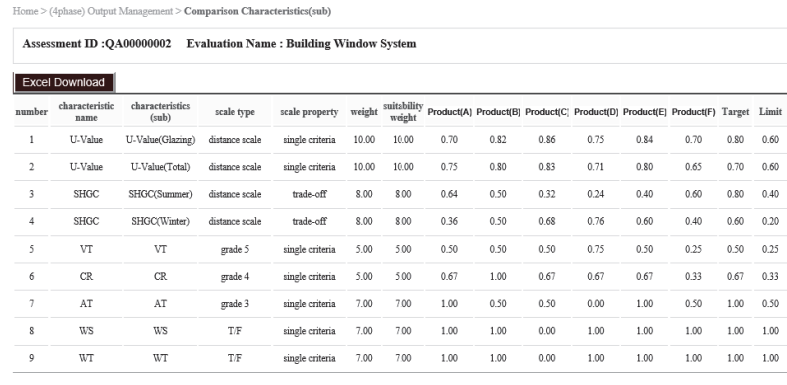

FIGURE 9: Comparison of the normalized TC values.

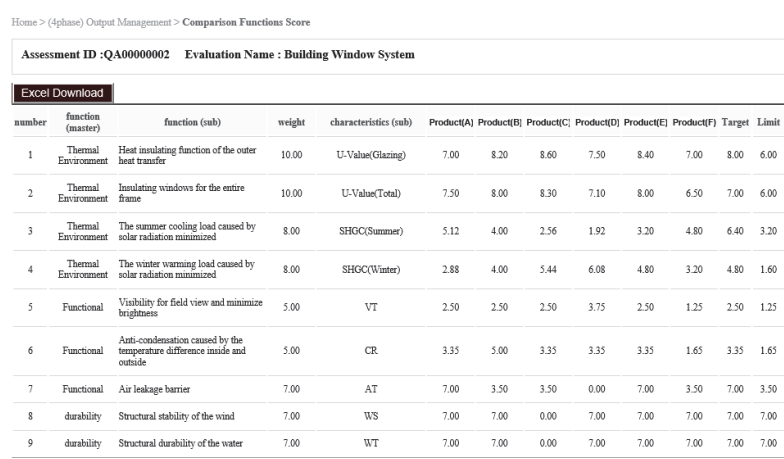

FIGURE 10: Comparison of the weighted TC values.

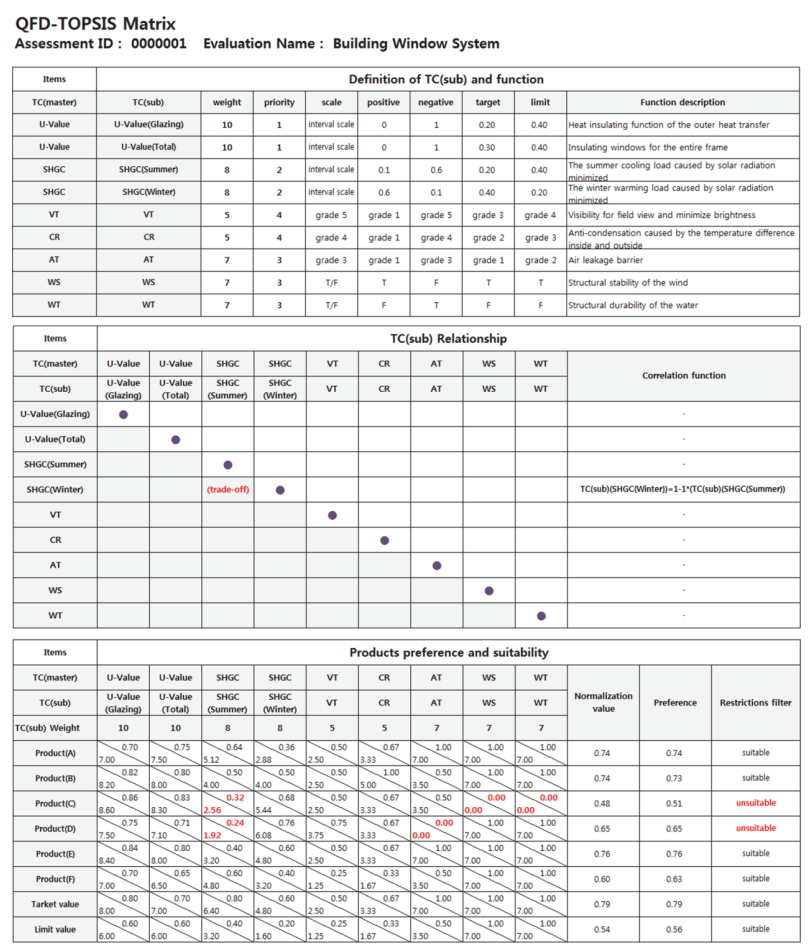

FIGURE 11: Denotation of trade-off TC(sub) and preferences for the market products. 


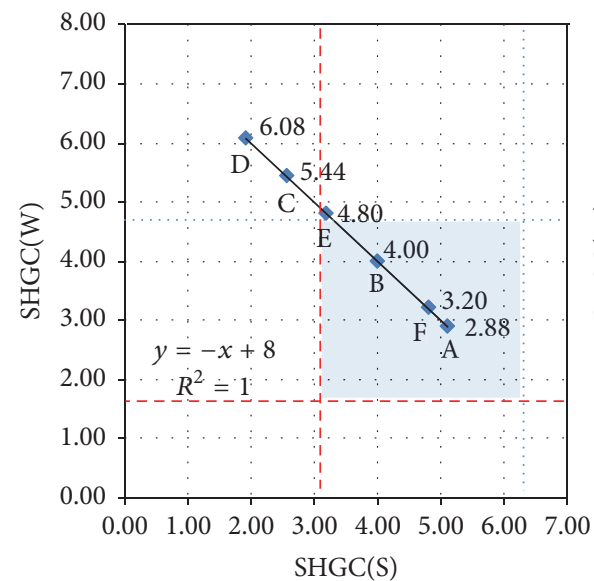

Sensitivity analysis (1)

-.- Limit value

Target value

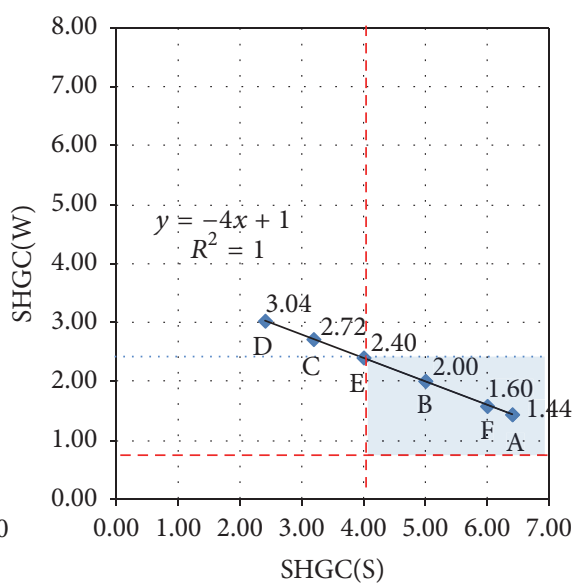

Sensitivity analysis (2)

- . - Limit value

Target value

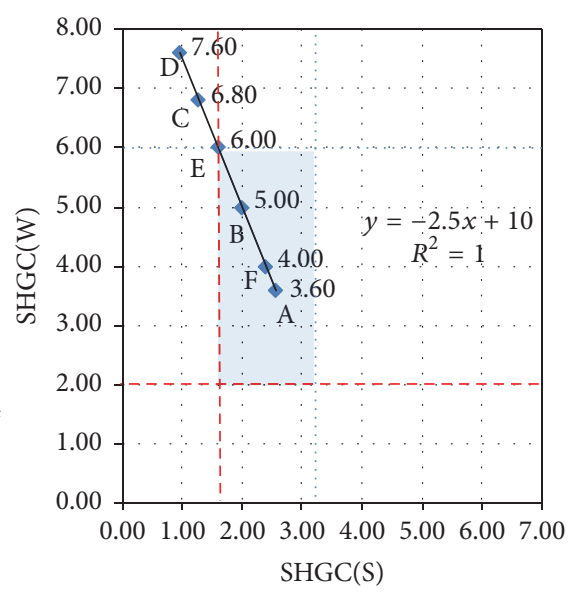

Sensitivity analysis (3)

- - - Limit value

Target value

Self-contradiction trade-offs

\begin{tabular}{|l|c|c|c|c|c|c|c|c|c|}
\hline Sensitive analysis (1) & Product(A) & Product(B) & Product(C) & Product(D) & Product(E) & Product(F) & Target & Limit & Weight \\
\hline SHGC(S) advantage & 5.12 & 4.00 & 2.56 & 1.92 & 3.20 & 4.80 & 6.40 & 3.20 & 8 \\
\hline SHGC(W) advantage & 2.88 & 4.00 & 5.44 & 6.08 & 4.80 & 3.20 & 4.80 & 1.60 & 8 \\
\hline
\end{tabular}

Self-contradiction trade-offs

\begin{tabular}{|l|c|c|c|c|c|c|c|c|c|}
\hline Sensitive analysis (2) & Product(A) & Product(B) & Product(C) & Product(D) & Product(E) & Product(F) & Target & Limit & Weight \\
\hline SHGC(S) advantage & 6.40 & 5.00 & 3.20 & 2.40 & 4.00 & 6.00 & 8.00 & 4.00 & 10 \\
\hline SHGC(W) advantage & 1.44 & 2.00 & 2.72 & 3.04 & 2.40 & 1.60 & 2.40 & 0.80 & 4 \\
\hline
\end{tabular}

Self-contradiction trade-offs

\begin{tabular}{|l|c|c|c|c|c|c|c|c|c|}
\hline Sensitive analysis (3) & Product(A) & Product(B) & Product(C) & Product(D) & Product(E) & Product(F) & Target & Limit & Weight \\
\hline SHGC(S) advantage & 2.56 & 2.00 & 1.28 & 0.96 & 1.60 & 2.40 & 3.20 & 1.60 & 4 \\
\hline SHGC(W) advantage & 3.60 & 5.00 & 6.80 & 7.60 & 6.00 & 4.00 & 6.00 & 2.00 & 10 \\
\hline
\end{tabular}

Product preference

\begin{tabular}{|l|c|c|c|c|c|c|}
\hline Preference & Product(A) & Product(B) & Product(C) & Product(D) & Product(E) & Product(F) \\
\hline Sensitive analysis (1) & 0.74 & 0.73 & 0.51 & 0.65 & 0.76 & 0.63 \\
\hline Sensitive analysis (2) & 0.76 & 0.74 & 0.49 & 0.63 & 0.76 & 0.64 \\
\hline Sensitive analysis (3) & 0.73 & 0.74 & 0.53 & 0.68 & 0.78 & 0.62 \\
\hline
\end{tabular}

Product preference rank

\begin{tabular}{|l|c|c|c|c|c|c|}
\hline Preference & Product(A) & Product(B) & Product(C) & Product(D) & Product(E) & Product(F) \\
\hline Sensitive analysis (1) & 2 & 3 & 6 & 4 & 1 & 5 \\
\hline Sensitive analysis (2) & 1 & 2 & 5 & 4 & 1 & 3 \\
\hline Sensitive analysis (3) & 3 & 2 & 6 & 4 & 1 & 5 \\
\hline
\end{tabular}

FIGURE 12: Sensitivity analysis of changes in the trade-off TC(sub) weights.

\section{Sensitivity Analysis}

Here, SHGC(S) and SHGC(W) are defined as "self-contradictory trade-off TC(sub)." The sensitivity analysis of the trade-off TC(sub) to alterations of the users' weights is shown in Figure 12
In "sensitivity analysis (2)," the weights for SHGC(S) and $\operatorname{SHGC}(\mathrm{W})$ were changed to 10 and 4, respectively, owing to the regional characteristic of the temperate climate. In "sensitivity analysis (3)," the weights for SHGC(S) and SHGC(W) were changed to 4 and 10 , respectively, owing to the regional characteristic of the microthermal climate. 
Based on the results obtained from the sensitivity analyses, different outcomes were observed with respect to the compensation effect, which is a monotonic decrease in the trade-off TC(sub) relation. It was confirmed that the tradeoff TC(sub) value is dependent on the definitions of the user weights. In addition, the overall product preferences for the alternative products changed with the trade-off TC(sub) weights. The subpreference ranks are shown in Figure 12.

\section{Conclusions}

This paper proposed a new advanced QFD-TOPSIS logic and the corresponding system for solving MCDM problems with regard to trade-off. The complex relationship and the subjective result of HOQ have hindered QFD from industrial application. Therefore, the present study combined TOPSIS with QFD to address the challenge.

The QFD-TOPSIS model is free of complex relationships between functions and TC through the simple 1:1 relations. The QFD-TOPSIS model can also clearly express the trade-off between TC that can be described by a mathematical correlation function. The QFD-TOPSIS logic not only measures the relative loss arising from trade-off TC, but also automatically analyzes the suitability of a product based on the predefined threshold of TC.

It also allows the QFD-TOPSIS system to compare multiple market products with the use of positive/negative ideal criteria and target and limit values. Finally, the model presents the preferred design solution made by considering user weights in the trade-off problem where the user needs to define priority TC for proper decision-making.

This test operation validated the MCDM solutions to address the objective and subjective comparison of construction product TC in a Web-based system. The case was conducted based on self-contradictory trade-off TC.

Additional tests, especially in the case of a pair of trade-off TC in other disciplines, are required to explore the preferences for employing the correlation functions of TC values. Further investigation is also required to extend the findings of this study to other fields, such as product suitability, safety analysis, and automatic quality check, where the requirements and standard criteria should be applied.

\section{Disclosure}

Jaeho Cho is the first author.

\section{Competing Interests}

The authors declare that there is no conflict of interests regarding the publication of this paper.

\section{Acknowledgments}

This research was supported by a grant (15AUDP-C06780903) from Architecture \& Urban Development Research Program funded by Ministry of Land, Infrastructure and Transport of Korean government. And this research was supported by Basic Science Research Program through the National Research Foundation of Korea (NRF) funded by the Ministry of Education (2015R1D1A1A01060356).

\section{References}

[1] J. R. S. C. Mateo, "Multi-criteria analysis," in Multi Criteria Analysis in the Renewable Energy Industry, Green Energy and Technology, pp. 7-10, Springer, Berlin, Germany, 2012.

[2] K. L. Edwards, "Selecting materials for optimum use in engineering components," Materials and Design, vol. 26, no. 5, pp. 469-473, 2005.

[3] Y. Tian, S. Wang, X. Bai, G. Luo, and Y. Xu, "Trade-offs among ecosystem services in a typical Karst watershed, SW China," The Science of the Total Environment, vol. 566-567, pp. 1297-1308, 2016.

[4] T. Yang and X. Zhang, "Benchmarking the building energy consumption and solar energy trade-offs of residential neighborhoods on Chongming Eco-Island, China," Applied Energy, vol. 180, pp. 792-799, 2016.

[5] X. Tang, B. C. McLellan, B. Zhang, S. Snowden, and M. Höök, "Trade-off analysis between embodied energy exports and employment creation in China," Journal of Cleaner Production, vol. 134, pp. 310-319, 2016.

[6] P. R. Drake, "Using the analytic hierarchy process in engineering education," International Journal of Engineering Education, vol. 14, no. 3, pp. 191-196, 1998.

[7] V. Kutut, E. K. Zavadskas, and M. Lazauskas, "Assessment of priority options for preservation of historic city centre buildings using MCDM (ARAS)," Procedia Engineering, vol. 57, pp. 657661, 2013.

[8] J. Rezaei, "Best-worst multi-criteria decision-making method," Omega, vol. 53, pp. 49-57, 2015.

[9] W. Sałabun, "The characteristic objects method: a new distancebased approach to multicriteria decision-making problems," Journal of Multi-Criteria Decision Analysis, vol. 22, no. 1-2, pp. 37-50, 2015.

[10] B. Vytautas, B. Marija, and P. Vytautas, "Assessment of neglected areas in Vilnius city using MCDM and COPRAS methods," Procedia Engineering, vol. 122, pp. 29-38, 2015.

[11] S. Greco, B. Matarazzo, and R. Słowiński, "Rough sets theory for multi-criteria decision analysis," European Journal of Operational Research, vol. 129, no. 1, pp. 1-47, 2001.

[12] M. K. Ghorabaee, E. K. Zavadskas, L. Olfat, and Z. Turskis, "Multi-criteria inventory classification using a new method of evaluation based on distance from average solution (EDAS)," Informatica (Netherlands), vol. 26, no. 3, pp. 435-451, 2015.

[13] B. O. Saracoglu, "An experimental research study on the solution of a private small hydropower plant investments selection problem by ELECTRE III/IV, Shannon's entropy, and Saaty's subjective criteria weighting," Advances in Decision Sciences, vol. 2015, Article ID 548460, 20 pages, 2015.

[14] J.-B. Yang and D.-L. Xu, "On the evidential reasoning algorithm for multiple attribute decision analysis under uncertainty," IEEE Transactions on Systems, Man, and Cybernetics Part A: Systems and Humans, vol. 32, no. 3, pp. 289-304, 2002.

[15] J. W. K. Chan and T. K. L. Tong, "Multi-criteria material selections and end-of-life product strategy: grey relational analysis approach," Materials \& Design, vol. 28, no. 5, pp. 15391546, 2007. 
[16] R. L. Keeney and H. Raiffa, Decisions with Multiple ObjectivesPreferences and Value Tradeoffs, Cambridge University Press, Cambridge, UK, 1993.

[17] A. Hafezalkotob, A. Hafezalkotob, and M. K. Sayadi, "Extension of MULTIMOORA method with interval numbers: an application in materials selection," Applied Mathematical Modelling, vol. 40, no. 2, pp. 1372-1386, 2016.

[18] S. Murat, H. Kazan, and S. S. Coskun, "An application for measuring performance quality of schools by using the PROMETHEE multi-criteria decision making method," Procedia-Social and Behavioral Sciences, vol. 195, pp. 729-738, 2015.

[19] R. Lahdelma and P. Salminen, "SMAA-2: stochastic multicriteria acceptability analysis for group decision making," Operations Research, vol. 49, no. 3, pp. 444-454, 2001.

[20] C. M. Tam, T. K. L. Tong, and Y. W. Wong, "Selection of concrete pump using the superiority and inferiority ranking method," Journal of Construction Engineering and Management, vol. 130, no. 6, pp. 827-834, 2004.

[21] X. Zhang and Z. Xu, "The TODIM analysis approach based on novel measured functions under hesitant fuzzy environment," Knowledge-Based Systems, vol. 61, pp. 48-58, 2014.

[22] J. Qin, X. Liu, and W. Pedrycz, "An extended TODIM multicriteria group decision making method for green supplier selection in interval type-2 fuzzy environment," European Journal of Operational Research, vol. 258, no. 2, pp. 626-638, 2017.

[23] C. L. Hwang and K. P. Yoon, Multiple Attribute Decision Making: Methods and Applications, vol. 186, Springer, New York, NY, USA, 1981.

[24] J. Cho and J. Chun, "Performance requirements on remodeling apartment housing and TOPSIS evaluation," Mathematical Problems in Engineering, vol. 2015, Article ID 357981, 12 pages, 2015.

[25] P. Wang, Z. Zhu, and Y. Wang, "A novel hybrid MCDM model combining the SAW, TOPSIS and GRA methods based on experimental design," Information Sciences, vol. 345, no. 1, pp. 27-45, 2016.

[26] S. Opricovic and G.-H. Tzeng, "Extended VIKOR method in comparison with outranking methods," European Journal of Operational Research, vol. 178, no. 2, pp. 514-529, 2007.

[27] M. Aghajani Mir, P. Taherei Ghazvinei, N. M. N. Sulaiman et al., "Application of TOPSIS and VIKOR improved versions in a multi criteria decision analysis to develop an optimized municipal solid waste management model," Journal of Environmental Management, vol. 166, pp. 109-115, 2016.

[28] http://www.hsor.org/what_is_or.cfm?name=mutli-attribute_ utility_theory.

[29] J. Cho, J. Chun, I. Kim, and J. Choi, "QFD based benchmarking logic using topsis and suitability index," Mathematical Problems in Engineering, vol. 2015, Article ID 851303, 13 pages, 2015.

[30] Y. Akao, "Development history of quality function deployment," in Proceedings of Customer Driven Approach to Quality Planning and Deployment, p. 339, Tokyo, Japan, 1994.

[31] J. A. Carnevalli and P. C. Miguel, "Review, analysis and classification of the literature on QFD-types of research, difficulties and benefits," International Journal of Production Economics, vol. 114, no. 2, pp. 737-754, 2008.

[32] I. Dikmen, M. T. Birgonul, and S. Kiziltas, "Strategic use of quality function deployment (QFD) in the construction industry," Building and Environment, vol. 40, no. 2, pp. 245-255, 2005.
[33] Y. Q. Yang, S. Q. Wang, M. Dulaimi, and S. P. Low, "A fuzzy quality function deployment system for buildable design decision-makings," Automation in Construction, vol. 12, no. 4, pp. 381-393, 2003.

[34] L.-K. Chan and M.-L. Wu, "A systematic approach to quality function deployment with a full illustrative example," Omega, vol. 33, no. 2, pp. 119-139, 2005.

[35] L.-H. Chen and W.-C. Ko, "Fuzzy approaches to quality function deployment for new product design," Fuzzy Sets and Systems, vol. 160, no. 18, pp. 2620-2639, 2009.

[36] R. Y. K. Fung, Y. Chen, and J. Tang, "Estimating the functional relationships for quality function deployment under uncertainties," Fuzzy Sets and Systems, vol. 157, no. 1, pp. 98-120, 2006.

[37] S. Yousefie, M. Mohammadi, and J. H. Monfared, "Selection effective management tools on setting European Foundation for Quality Management (EFQM) model by a quality function deployment (QFD) approach," Expert Systems with Applications, vol. 38, no. 8, pp. 9633-9647, 2011.

[38] Y. Lin, H.-P. Cheng, M.-L. Tseng, and J. C. C. Tsai, "Using QFD and ANP to analyze the environmental production requirements in linguistic preferences," Expert Systems with Applications, vol. 37, no. 3, pp. 2186-2196, 2010.

[39] H. Raharjo, A. C. Brombacher, and M. Xie, "Dealing with subjectivity in early product design phase: a systematic approach to exploit quality function deployment potentials," Computers \& Industrial Engineering, vol. 55, no. 1, pp. 253-278, 2008.

[40] C. Garibay, H. Gutiérrez, and A. Figueroa, "Evaluation of a digital library by means of quality function deployment (QFD) and the Kano model," The Journal of Academic Librarianship, vol. 36, no. 2, pp. 125-132, 2010.

[41] M. Azadi and R. Farzipoor Saen, "A combination of QFD and imprecise DEA with enhanced Russell graph measure: a case study in healthcare," Socio-Economic Planning Sciences, vol. 47, no. 4, pp. 281-291, 2013.

[42] Y.-L. Li, J.-F. Tang, K.-S. Chin, Y. Han, and X.-G. Luo, "A rough set approach for estimating correlation measures in quality function deployment," Information Sciences, vol. 189, pp. 126142, 2012.

[43] T. Park and K.-J. Kim, "Determination of an optimal set of design requirements using house of quality," Journal of Operations Management, vol. 16, no. 5, pp. 569-581, 1998.

[44] M. E. Pullman, W. L. Moore, and D. G. Wardell, "A comparison of quality function deployment and conjoint analysis in new product design," Journal of Product Innovation Management, vol. 19, no. 5, pp. 354-364, 2002.

[45] H. Moskowitz and K. J. Kim, "QFD optimizer: a novice friendly quality function deployment decision support system for optimizing product designs," Computers \& Industrial Engineering, vol. 32, no. 3, pp. 641-655, 1997.

[46] D. Ginn and M. Zairi, "Best practice QFD application: an internal/external benchmarking approach based on Ford Motors' experience," International Journal of Quality and Reliability Management, vol. 22, no. 1, pp. 38-58, 2005.

[47] W. Yan, L. P. Khoo, and C.-H. Chen, "A QFD-enabled product conceptualisation approach via design knowledge hierarchy and RCE neural network," Knowledge-Based Systems, vol. 18, no. 6, pp. 279-293, 2005.

[48] S. M. Ahmed, L. P. Sang, and Ž. M. Torbica, "Use of quality function deployment in civil engineering capital project planning," Journal of Construction Engineering and Management, vol. 129, no. 4, pp. 358-368, 2003. 
[49] Z. S. Xu and R. R. Yager, "Dynamic intuitionistic fuzzy multiattribute decision making," International Journal of Approximate Reasoning, vol. 48, no. 1, pp. 246-262, 2008.

[50] M. Li, L. Jin, and J. Wang, "A new MCDM method combining QFD with TOPSIS for knowledge management system selection from the user's perspective in intuitionistic fuzzy environment," Applied Soft Computing, vol. 21, pp. 28-37, 2014.

[51] K. P. Yoon and C. Hwang, Multiple Attribute Decision Making: An Introduction, SAGE, California, Calif, USA, 1995.

[52] E. K. Zavadskas, A. Zakarevicius, and J. Antucheviciene, "Evaluation of ranking accuracy in multi-criteria decisions," Lithuanian Academy of Sciences. Informatica (Vilnius), vol. 17, no. 4, pp. 601-618, 2006.

[53] S. Sivaloganathan, N. F. O. Evbuomwan, A. Jebb, and H. P. Wynn, "Design function deployment-a design system for the future," Design Studies, vol. 16, no. 4, pp. 447-470, 1995.

[54] F. Yasamis-Speroni, D.-E. Lee, and D. Arditi, "Evaluating the quality performance of pavement contractors," Journal of Construction Engineering and Management, vol. 138, no. 10, pp. 11141124, 2012. 


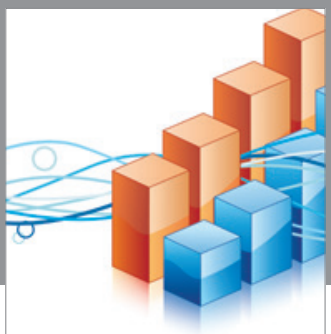

Advances in

Operations Research

vatem alat4

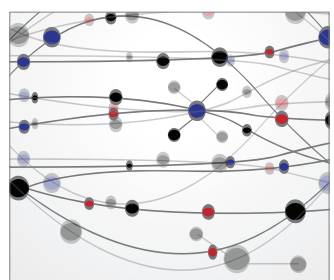

\section{The Scientific} World Journal
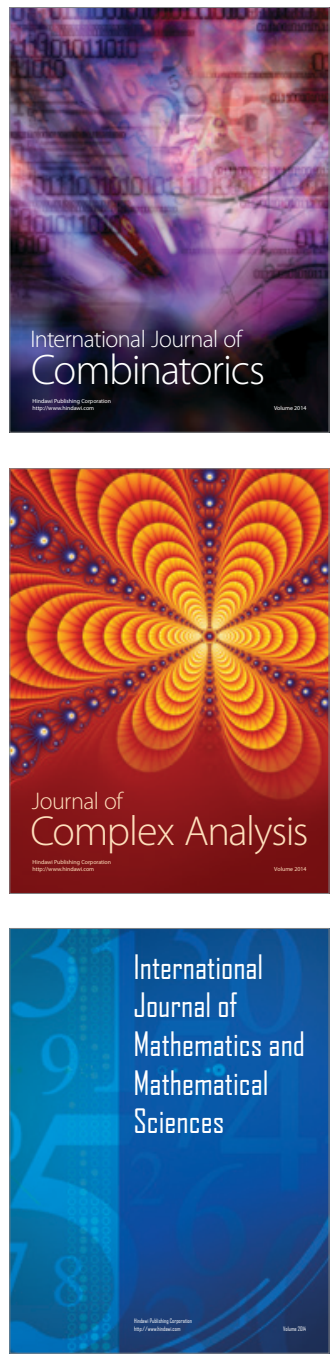
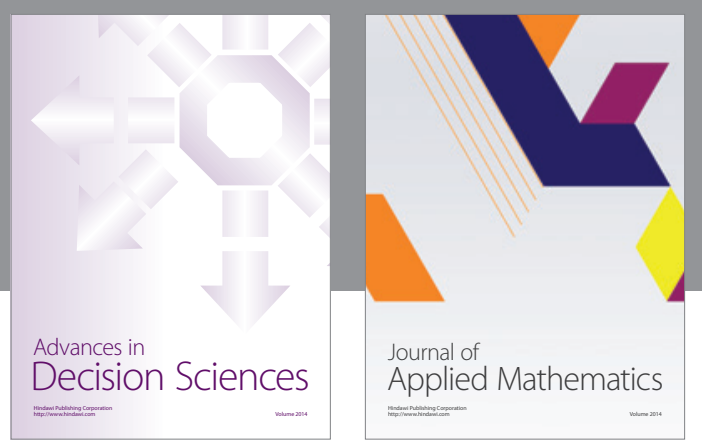

Algebra

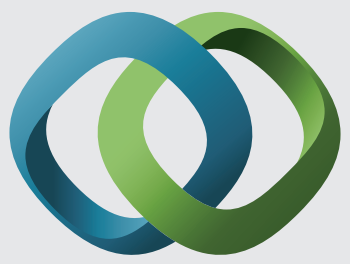

\section{Hindawi}

Submit your manuscripts at

https://www.hindawi.com
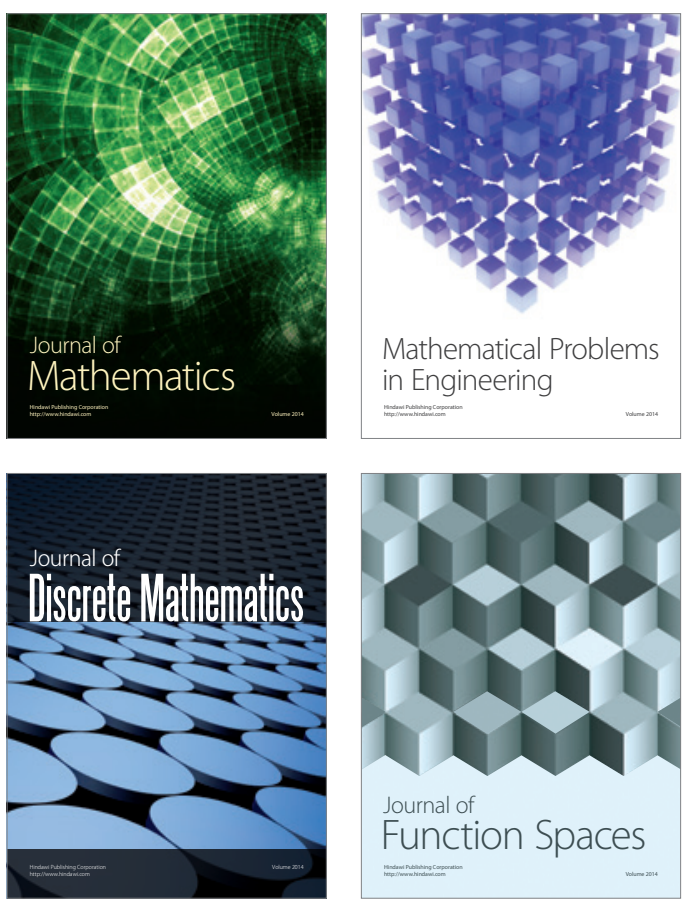

Mathematical Problems in Engineering
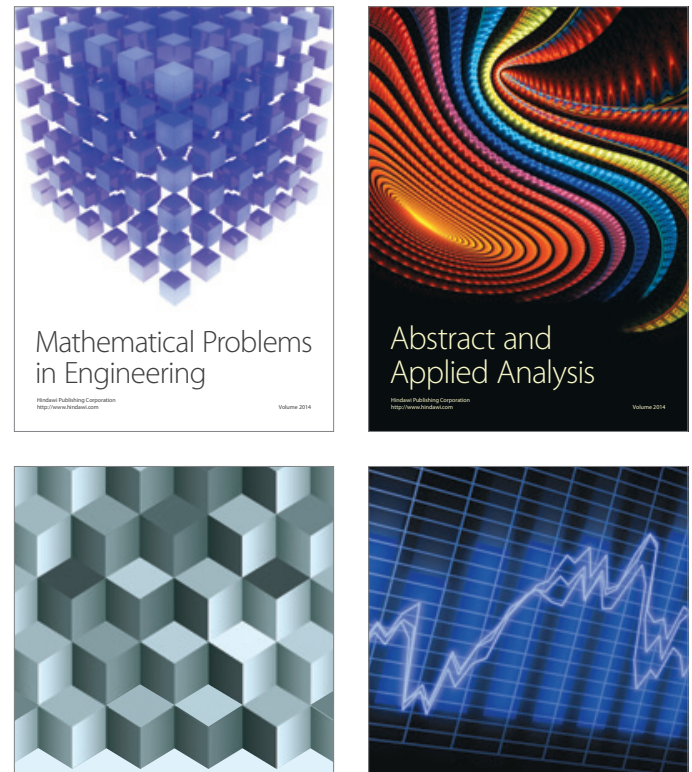

Journal of

Function Spaces

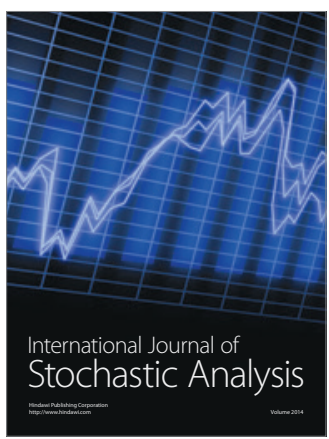

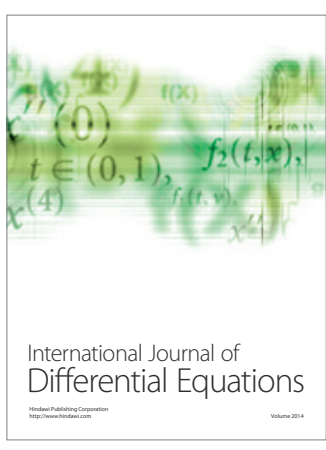
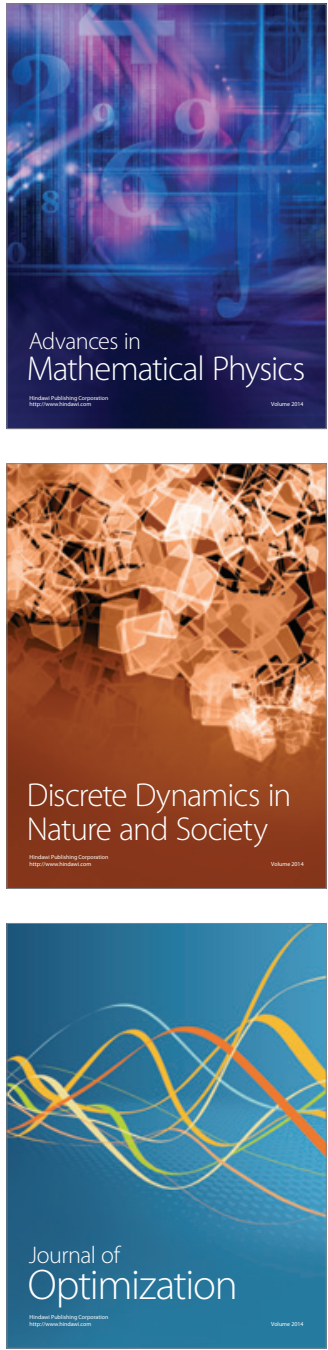